\title{
Waramopoy dan Kelentangan Dalam Upacara Kwangkay Pada Suku Dayak Benuaq di Kalimantan Timur
}

\begin{abstract}
Asti Hamdani ${ }^{1}$
Abstract

Kwangkay is one of the most recent death ceremonies of all the processes of death ritual that found in the Dayak Benuaq, East Kalimantan. This ceremony is doing by digging back the ancestral bones of the deceased and has been buried for 4 years or more. The bones are led by pengewara (traditional leader). Wara Mopoy is a vocal art form of a mantra recited by the rulers during the routine ritual of giving food to the spirits of the ancestors in every day and it is believed to be the medium to deliver the soul to the highest cosmos (Lamut Paradise). During the ritual process, there is also a musical opposition that serves as a dance accompaniment Ngerangkaw (the dance that carried bones in the back).

Death becomes something that passes by certain rules and ritual levels because they believe that the nature of the paradise has different levels according to the level of ceremony performed by the living (family and relatives). This kwangkay ceremony is closely related to the origins and mythology of the Dayak tribe of Benuaq that has shaped and bound them in a Benuaq customary and customary order. Implementation was through a variety of requirements, stages, and complicated process to take 21 days.
\end{abstract}

Keywords: kwangkay, wara mopoy, kelentangan.

\begin{abstract}
Abstrak
Kwangkay adalah salah satu upacara kematian yang paling akhir dari semua proses ritual kematian yang terdapat pada kepercayaan suku Dayak Benuaq, Kalimantan Timur. Upacara ini dilakukan dengan menggali kembali tulang-belulang leluhur yang telah lama meninggal dan telah dikuburkan selama 4 tahun atau lebih. Tulang-belulang tersebut diupacarai dengan dipimpin oleh pengewara(pawang adat). Wara Mopoy adalah bentuk seni suara/vokal yang berupa mantra yang dibacakan pengewara ketika ritual rutin pemberian makanan kepara arwah leluhur di setiap harinya dan dipercaya sebagai media untuk menghantarkan arwah sampai ke dunia kosmos tertinggi (surga Lamut). Selama proses ritual, terdapat pula musik kelentangan yang berfungsi sebagai pengiring tarian Ngerangkaw (tarian penggendongan tulang-belulang).
\end{abstract}

\footnotetext{
${ }^{1}$ Mahasiswa Jurusan Etnomusikologi FSP ISI Yogyakarta, email : astiside30@ gmail.com.
} 
Kematian menjadi sesuatu yang dilalui berdasarkan aturan dan tingkatan ritual tertentu karena mereka percaya bahwa alam baqa memiliki tingkat kehidupan yang berbeda sesuai dengan tingkat upacara yang dilaksanakan orang yang masih hidup (keluarga dan kerabat). Upacara kwangkayini terkait erat dengan asal usul dan mitologi suku dayak Benuaq yang telah membentuk dan mengikat mereka dalam suatu tatanan norma dan aturan adat Benuaq secara turun-temurun. Pelaksanaannya pun melalui berbagai syarat, tahapan, dan proses yang rumit hingga memakan waktu 21 hari.

Kata kunci: kwangkay, wara mopoy, kelentangan.

\section{Pendahuluan}

Semua manusia yang hidup pasti akan mati. Kematian akan disikapi berbeda oleh setiap kebudayaan dan adat istiadat di setiap daerah. Sama halnya dengan suku Dayak Benuaq yang ada di Kalimantan Timur.Mereka memiliki cara yang khas dalam menyikapi kematian. Kematian dalam siklus kehidupan suku dayak Benuaq merupakan suatu tahapan penting menuju tingkatan kosmos selanjutnya. Meninggalnya seseorang bukan berarti hubungannya antara manusia yang hidup telah berakhir. Akan tetapi, arwah dipercaya akan berada pada suatu alam persinggahan, menjaga kampung sekitar 4 hingga 7 tahun lamanya. Keluarga yang masih hidup wajib menghantarkan arwah ke alam tertinggi yang paling baik melalui suatu tahapan upacara ritual.

Upacara ritual yang dilaksanakan oleh dayak Benuaq memiliki tiga tingkatan semenjak seseorang baru dikatakan meninggal. Tingkatan ini menyesuaikan dengan tingkat surga (lamut) yang terdapat dalam ajaran kepercayaan Jurikng Olo dan Danah Olo dalam mitologi suku dayak Benuaq. Semakin tinggi tingkat upacara kematian yang dilaksanakan, maka semakin tinggi pula tingkatan surga yang akan ditempati oleh para arwah. Upacara tingkat paling bawah yang pertama kali dilaksanakan setelah kematian disebut PerampApi dengan lama ritual 7 hari. Tingkatan selanjutnya disebut Kenyau, dengan lama ritual 7 hari hingga 9 hari dan dilaksanakan setelah Peramp Api. Sedangkan dalam tulisan ini akan membahas ritualkwangkay yang merupakan ritual terakhir dan dipercaya sebagai tingkatan paling tinggi dalam upacara kematian suku Dayak Benuaq. 
Kwangkay berasal dari kata ke yang berarti melakukan/melaksanakan dan angkey yang berarti jasad/mayat yang sudah tidak bernyawa lagi.Kwangkay artinya adalah melaksanakan upacara adat jasad tulang belulang atau adat bagi orang yang telah lama meninggal dengan pengorbanan dan penghormatan yang sebesar-besarnya. (Emanuel, 2013: 31).

Upacara tingkatan kematian yang paling tinggi dan terakhir ini juga memiliki arti bahwa dari serangkaian ritual kematian yang ada, kwangkay memiliki proses yang paling rumit dan kompleks karena berlangsung selama 2149 hari berdasarkan perhitungan khusus.Perhitungan kelipatan 7 hari ini merupakan angka ganjil sebagai simbol kematian.Terhitung 4-7 tahun semenjak jasad dikuburkan, kwangkay telah dapat dilaksanakan karena jasad telah berubah menjadi tulang-belulang.

Tulang belulang mayat terdahulu diangkat/ digali kembali dan dibersikan dengan menggunakan air kelapa.Setelah itu dipindahkan ke dalam rumah adat (lou adat). Kemudian ketua adat yang menjadi pawang (pengewara) akan memanggil arwah dengan mantra tertentu. Mantra yang dinyanyikan dengan nada khusus dan dalam Bahasa Benuaqtingkat arwah itu disebut wara.Arwah yang diundang datang kemudian dijamu dan diberi makan setiap pagi dan malam hari selama 14 hingga 21 hari.Ritual pemberian makan arwah ini disebut mopoy.Acara mopoy ini merupakan acara rutin dan wajib setiap harinya selama upacara berlangsung. Selanjutnya ketika malam hari, 14 orang penari akan menarikan tarian yang disebut ngerangkaw. Tengkorak dan tulang-belulang leluhur dibalut kain batik kemudian dibawa menari dengan cara digendong serta diiringi oleh ansambel musik kelentangan dengan suasana sakral.

Rangkaian proses ritual kwangkay tersebut tidak terlepas dari mantra (wara mopoy) yang merupakan bagian yang penting karena banyak mengandung makna, tata cara, tuntunan, pola komunikasi kepada para roh, serta kepercayaan kepada tuhan dan roh leluhur yang tetap dipertahankan oleh beberapa penganutnya hingga sekarang. Kesatuan rangkaian acara yang berisi mantramantra (wara) oleh dukun adat (pengewara), tarian, dan alunan musik kelentangan yang mistik tersebut diperkuat juga oleh beberapa syarat-syarat dan 
sesaji.Persembahan berupa sesaji dan hewan ternak yaitu kerbau, babi, serta ayam, menjadi syarat mutlak dalam upacara ini.Sekurang-kurangnya keluarga harus mengeluarkan biaya puluhan hingga ratusan juta rupiah untuk melaksanakan rangkaian acara ritual ini.

Tradisikwangkay yang masih dipertahankan ini sekaligus sebagai cara suku dayak Benuaq menjaga tradisi balas budi (malas budi) kepada orang tua atau leluhur mereka dan tradisi gotong-royong antar sesama. Walaupun demikian, kelompok suku Dayak Benuaq sebenarnya tidak sedikit juga yang telah meninggalkan tradisi ini karena perubahan keyakinan dengan menganut agama resmi seperti Kristen Katolik dan Kristen Protestan, sehingga tata cara kematian sesuai dengan keyakinan dari agama mereka tersebut.Akan tetapi, masih ada kelompok yang memilih tetap melaksanakan dan menyikapi untuk mempertahankan kearifan lokal khas mereka meskipun memakan biaya dan waktu yang tidak sedikit.Kelompok yang tetap mempertahan nilai tradisi ini percaya akanberbagai kekuatan antara alam dan manusia yang harus selalu diseimbangkan baik secara vertikal maupun horisontal. Makna dan pesan simbolik yang masih dipertahankan ini menarik peneliti untuk mencari lebih dalam mengapa upacara tersebut masih dijalankan dan dipercayai oleh masyarakat penganutnya hingga sekarang.

\section{Proses dan Makna Upacara Kwangkay}

Kematian menurut dayak Benuaq merupakan suatu peristiwa keluarnya roh kehidupan (juus) yang meninggalkan tubuh (unuk), untuk selanjutnya mulai mengembara di alam tertentu hingga sampai ditempat peristirahatan terakhir.(Suwardi, 1986: 13)Juus yang telah meninggalkan unuk berubah nama kemudian disebut liau dan kelelungan. Di kalangan masyarakat Dayak Benuaq, liau dianggap sebagai roh yang berasal dari anggota badan di bawah kepala yaitu tenaga, tubuh, badan, daging, darah, dan tulang. Bila seseorang meninggal dunia dan dikuburkan, maka badan akan hancur, namun roh badan tersebut akan tetap hidup. Kelelungan dianggap sebagai roh fikiran atau jiwa tengkorak, yang berasal dari anggota badan bagian kepala.Kelelungan cenderung bersifat baik bahkan 
dapat menjadi perantara manusia dalam mengadakan hubungan dengan tuhan.Walaupun demikian, bukan berarti kedua jiwa tersebut berwujud setengahsetengah, melainkan tetap merupakan kesatuan yang utuh.

Roh yang berubah menjadi liau dan kelelungan hanya dapat terjadi jika jasadnya yang berupa tulang-belulang sudah dibersihkan dalam tahapan yang disebut tenulaakng (bagian dari prosesi kwangkay). Ketika jasad belum berubah menjadi tulang-belulang dan dibersihkan pada proses tenulakng tersebut, maka roh masih menempati alam lamut pada tingkatan yang bawah.Tempat persemayaman akhir liau dan kelulungan juga berbeda.Menurut kepercayaan Benuaq alam akhirat terbagi dua yaitu Lamut dan Tenangkai.Liauakantinggal di lumut dan kelelunganakan tinggal di Tenangkai ketika telah diadakan ritual kwangkay.

Tahapan awal yang dilakukan sebelum untuk memulai upacara kwangkay adalah persiapan dengan mengumpulkan keluarga besar untuk memusyawarahkan segala sesuatunya.Setelah ada persetujuan, kemudian ditentukanlah waktunya berdasarkan perhitungan khusus. Biasanya biaya yang dilakukan untuk proses kwangkay ini berasal dari gotong royong beberapa anggota keluarga yang dikumpulkan selama beberapa tahun. Biaya yang dikeluarkan dapat mencapai 50 hingga 100 juta rupiah ataupun bahkan lebih. Setelah dana terkumpul, kemudian mempersiapkan panitia dan memilih pawang untuk acara. Anggota panitia dapat berjumlah hingga 50 orang atau lebih yang terdiri dari 3 orang pawang adat (pengewara), 2 orang penasehat adat (biasanya berasal dari dewan adat atau ketua adat setempat), 5 orang bertugas di bagian perlengkapan, 4 orang petugas keamanan, 4 orang bertugas memainkan musik, dan sisanya bertugas sehari-hari dalam prosesi tarian ngerangkau maupun mempersiapkan berbagai syarat upacara. Pembagian panitia ini berasal dari anggota keluarga atau dari luar keluarga (kerabat dekat atau tetangga).Persiapan juga dilakukan oleh anggota keluarga dengan membuat ijin secara adminitratif kepada beberapa kepala daerah stempat.Ijin harus melalui tahapan kepada pihak RT, RW, kelurahan, kecamatan, dan dewan adat setempat.Kemudian mendaftarkan kepada dinas pariwisata untuk meminta ijin adat serta ijin keramaian kepada polisi setempat. 
Bagian paling penting dalam proses persiapan ini juga harus memenuhi kelengkapan-kelengkapan dan syarat-syarat seperti alat musik (domaq) yang terdiri dari gong, gimar, dan kelentangan. Kemudian mempersiapkan persembahan yang berupa babi, ayam, dan kerbau yang disebut hewan kurban, serta sesaji dan perlengkapan untuk menjamu dan mengantarkan arwah.Setelah dianggap sudah benar-benar siap segala sesuatunya, acara pun dapat dimulai.

Setiap pagi dan malamnya pengewara (pawang) harus memanggil para arwah dari alam lain untuk diberikan makan dan minum selayaknya mereka masih hidup, dan ini wajib dilakukan setiap pagipukul 10.00 WITA dan malam hari pukul 06.00 WITAhingga hari ke 21 acara berakhir. Lama ritual memberi makan (mopoy) ini biasanya menyesuaikan dengan isi lantunan mantra (wara) yaitu sekitar 15 hingga 20 menit.Sesaji yang dihidangkan untuk arwah tersebut dibagi menjadi dua jenis.Jenis pertama adalah makanan yang dihidangkan untuk roh badan (liau) dengan ditutup oleh kain berwarna merah.Jenis kedua adalah makanan yang dihidangkan untuk roh jiwa (kelelungan) dengan ditutup oleh kain berwarna putih.

Pelaksanaan ritual pemberian makan arwah secara prosesnya ini tidak ada perbedaan di hari-hari selanjutnya. Namun ada hal yang membedakan, setiap harinya pengewaraakan membacakan berbagai macam riwayat manta (wara)/ dongeng asal-usul yang berbeda. Dongeng riwayat asal usul tersebut dilantunkan menggunakan bahasa khusus. Sebagian ucapan pengewara tersebut ada yang dapat dimengerti dan sebagian juga tidak, jika melihat pendekatan menurut bahasa asli suku dayak Benuaq. Sebagian kata-kata yang diucapkan oleh pengewaraakan menggunakan pola komunikasi khusus kepada para roh. Ucapan ini dipercayai sebagai wahyu yang hanya seseorang yang dianggap telah tutus(sakti) terhadap adat kematian yang mengetahuinya. Namun jika diceritakan berdasarkan alur mantranya, maka isi dan konteks riwayat mantra wajib untuk ritual pemberian makan arwah (mopoy) dibagi sebagai berikut.

a. Hari ke 1 waratunaang (pembukaan ritual), pawang meriwayatkan asal usul api dan dupa

b. Hari ke 2 pawang meriwayatkan asal usul langit dantana (tanah) 
c. Hari ke 3 pawang meriwayatkan asal usul beras

d. Hari ke 4 meriwayatkan asal usul ayam

e. Hari ke 5 meriwayatkan asal usul babi

f. Hari ke 6 meriwayatkan asal usul selimaat (kotak tempat tulangbelulang)

g. Hari ke 7 mulaingerangkaw (arwah menari), riwayat asal usul selimat, bambu, dan balok, dan domaq (alat musik).

h. Hari ke 8 meriwayatkan asal usul rotan dan pemala (makanan arwah).

i. $\quad$ Hari ke 9 meriwayatkan asal usul lamin (rumah adat)

j. Hari ke 10 meriwayatkan asal usul air

k. Hari ke 11 meriwayatkan asal usul kematian (tempuutn mate), dan kayu ulin (teluyatn).

1. Hari ke 12 meriwayatkan asal usul lou/lamin (rumah pangjang), pulut (ketan), dan buah-buahan (sensiwo uluq).

m. Hari ke 13 meriwayatkan asal usul makanan arwah

n. Hari ke 14 meriwayatkan asal usul tumbuhan (biyowo bentolaatn)

o. Hari ke 15 meriwayatkan asal usul kwangkay

p. Hari ke 16 meriwayatkan asal usul ajaran saling melayani

q. Hari ke 17 meriwayatkan asal usul benda sesaji

r. Hari ke 18 meriwayatkan asal usul hewan kurban kerbau, ulaas arikng (penghargaan kepada arwah).

s. Hari ke 19 mantra(wara) encooi talitn pakat seleeu (undangan roh liau dan kelelungan)

t. Hari ke 20 mantra(wara) entookng liaau seleeu (jemput para arwah).

u. Hari ke 21 ukaai solaai (acara puncak bunuh kerbau), mantra(wara) encooi liaau (mengantar arwah ke peristirahatan yang terakhir) (Yotam, Wawancara,29 Februari 2017)

Selain mantra wajib di atas yang harus dibacakan ketika ritual pemberian makan arwah, adapula mantra lain yang bertujuan sebagai komunikasi pengewara untuk menyampaikan maksud, tujuan dan pesan-pesan keluarga yang menyelenggarakan kwangkay.

Musik kelentangan dihadirkan ketika hari ke tujuh dimulainya prosesi menari Ngerangkaw.Tari Ngerangkaw dilakukan untuk perjalanan menghantarkan arwah yang dipercayai akan sampai surga. Para arwahakan diantarkan ke sebuah gunung sebagai surga tempat tinggal para roh yaitu Lamut dan Tenangkai. Tari Nerangkaw ini dilakukan oleh 14 orang yang terdiri dari 7 orang laki-laki dan 7 orang perempuan. Tarian ini dilakukan dengan mengelilingi kotak selimat dan 
awir batu raja (langit-langit di atas selimat) yang berada di tengah rumah, sebanyak 7 kali putaran serta arah putaran berlawanan dengan arah jarum jam.

Demikian halnya dengan musik kelentangan, membantu gerakan tubuh penari untuk menghasilkan gerakan tari.Penari yang bergerak mengikuti irama dengan susunan ritmis teratur kemudian membentuk satu kesatuan simbol yang menghantarkan mereka berhubungan dengan kosmos.Gerakan yang dihasilkan mulanya dengan melangkahkan kaki ke depan dan menghentakkan salah satu kaki di belakang seirama dengan musik. Kedua tangan diayunkan kesamping atas dan seperti gerakan burung terbang, serta ada gerakan yang menunjukkan badan condong ke samping kanan dan kiri mengikuti hentakan dan langkah kaki. Gerakan tari yang melangkah maju terus ke arah depan kemudian mengelilingi lamin membentuk lingkaran penuh yang berulang.

Musik berperan juga untuk menjaga konsentrasi penari dalam melakukan penyatuan diri dengan alam sekitar yang dipercayai memiliki hubungan erat dengan alam roh sehingga dapat mengantarkan para arwah ke alamnya.Musik juga sebagai persembahan kepada leluhur yang ditandai dengan rasa suka cita, karena mereka percaya bahwa musik kelentangan ini dapat menyenangkan para arwah tersebut.Akan tetapi, tidak semua penari dapat menari sambil membawakan tulang-belulang roh leluhur melainkan hanya keluarga terdekat dan pengewara yang diperbolehkan.Tulang-belulang tersebut dibalut dengan kain batik dan di gendong di belakang pundak penari.

Jauh hari sebelumnya keluarga sudah menyiapkan tempat tulang belulang dari kayu ulin (tempelaaq) dan memperbaiki kuburan-kuburan lama yang telah rusak. Kemudian membuat patung besar dari ulin (belontaakng)untuk mengikat kerbau ketika akan ditombak sebagai kurban untuk para arwah. Selain itu, harus menyiapkan kesuncookngatau tempat mengurung kerbau sebelum dilepaskan, serta selampit tali ikat kerbau dari rotan sebanyak 7 biji rotan.Ketika seluruh persiapan dan perlengkapan ritual sudah dianggap memenuhi syarat, maka tibalah saatnya hari puncak bunuh kerbau dan biasanya jatuh pada hari ke 21 yang disebut ukaai solaai.Selanjutnya pada malam hari ritual yang dilakukan adalahtangaai (para arwah berpamitan), ruraatn engelio (acara penutupan), serta 
pembagian lalus (upah kepada pacara pengewara dan semua pihak yang membantu ritual kwangkay).

Selain mengadakanwara mopoy dan tarian ngerangkaw, setiap malamnya acara rutin yang ada dalam upacara kwangkay ini adalah judi dan setiap hari sabtu minggu diadakan sabung ayam.Keadaan kampung menjadi sangat ramai karena berlangsung sepanjang malam.Berdasarkan permainan judi tersebut, sepuluh persen dari pendapatan hasil bermain judi wajib disalurkan untuk upacara adat.Berbagai lapak para pedagang makanan, minuman juga membawa berkah tersendiri karena sebagai lahan bisnis warga setempat untuk sementara waktu kampung/desa mereka sedang diramaikan oleh acara tersebut.

Upacara kwangkay ini sebagai suatu tahapan tertentu dalam masyarakat Benuaq dalam memandang arti sebuah kematian.Penghormatan terhadap kepercayaan leluhur ini merupakan simboldari sebuah tradisi yang turun temurun. Kemudian dalam pelaksanaan upacara ini memiliki makna dan arti penting bagi masyarakat dayak Benuaq, baik makna sosial maupun spiritual. Hewan-hewan yang dikorbankan dalam upacara itu, ternyata bukan hanya dari kalangan keluarga yang meninggal, tetapi juga merupakan bantuan dari semua keluarga dan kerabat.Selain itu, hewan yang dikorbankan itu juga dibagi-bagikan kepada warga sekitar.Sehingga ini menjadi simbol nilai-nilai dari upaya melestarikan tradisi tolong-menolong/ gotong-royong serta balas budi kepada leluhur.

Secara spiritual pun upacara ini menghubungkan aspek vertikal antara manusia dengan kepercayaan religius oleh dayak Benuaq mengenai ruang antara pemisah kehidupan dan kematian. Sehingga penyikapan khusus yang dilakukan oleh adat menandakan penghargaan yang tinggi terhadap keberadaan dan eksistensi hadirnya manusia di dunia.Hal ini dapat terlihat dari aspek lantunan makna dan isi mantra yang meriwayatkan ajaran mitologi mereka mengenai berbagai hakikat kehidupan yang ditunjukan kepada para roh leluhur.Isi cerita asal usul tersebut dipercaya menjadi tuntunan dan pengetahuan untuk para roh untuk sampai ke tempat terbaiknya di alam akhirat. 


\section{Bentuk Penyajian Wara Mopoy dan Musik Kelentangan}

Bagian pertama dari penyajian wara mopoy adalah musik vokal yang dilantunkan dengan nada dan gaya khas atau biasa disebut pula dengan mantra. Mantra ini dapat berbentuk vokal tunggal dan ada juga bagian yang dilantunkan bersamaan dengan dua atau tiga orang pengewara. Berikut adalah contoh mantra yang dilantunkan bersamaan dengan beberapa pengewara lain ketika memulai ritual mopoy.

Pola nada wara. Do $=$ Es

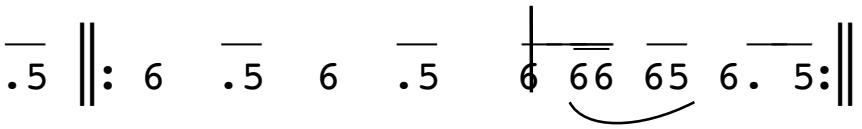

$$
\begin{aligned}
& \text { bo tek pen cit neng ka yo } m \text { o noi } \\
& \text { lou gu ookng galu uu bo teq tu } \\
& \text { naaunge re wa aumo no } i \text { de } \\
& \text { ooq } t i \quad a \quad \text { aq } \quad \text { ma } a \text { o } o q
\end{aligned}
$$

Arti terjemahan bebas dari penggalan mantra tersebut adalah memohon para arwah yang menari tidak meloncat-loncat bagaikan rusa agar lamin tidak roboh, janganlah menari bagaikan kerbau mengamuk agar anak-anak kami tidak ketakutan. (Daniel, Wawancara, 2 Maret 2016).Ini adalah semacam permohonan untuk para arwah yang dipercaya ikut menari ketika prosesi tari Ngerangkaw.

Gaya bernyanyi yang diterapkan dalam mantra ini memiliki karakter melodi yang sederhana namun khas. Dilihat dari motif nada yang hanya menggunakan 2 nada, dan pada akhiran nada biasanya terjadi penambahan cengkok yang diperlihatkan dengan legato dalam rentang nada yang tidak begitu jauh.

Syair mantra merupakan doa yang kemanjurannya sangan tergantung pada kualitas kesucian orang yang mengucapkannya. Syair ini merupakan kata-kata yang penuh arti dan sangat rahasia sifatnya, sehingga syair mantra dianggap sebagai bunyi-bunyian ritual yang sacral (Senen, 2015: 112). Mantra (wara mopoy) tersebut menggunakan bahasa yang dianggap sakral karena merupakan bahasa kuno yang dipercayai hanya untuk berkomunikasi dengan para roh leluhur, sehingga bukan merupakan bahasa dayak Benuaq yang lazim digunakan sehari- 
hari. Selain itu banyak juga digunakan kata kiasan dan bahasa simbolik dari katakata yang terdapat dalam mantra.Contohnya penggunaan pengandaian dan majas metafora dan makna konotasi, mengibaratkan rusa atau kerbau, serta digunakan untuk menafsirkan permohonan kepada arwah sebagai janji untuk tidak mengganggu.Bentuk mantra ini tidak terikat oleh bunyi akhiran huruf berakhiran bebas.Selanjutnya adapun mantra tunggal yang diucapkan secara bergantian dengan memikili pola nada sebagai berikut.

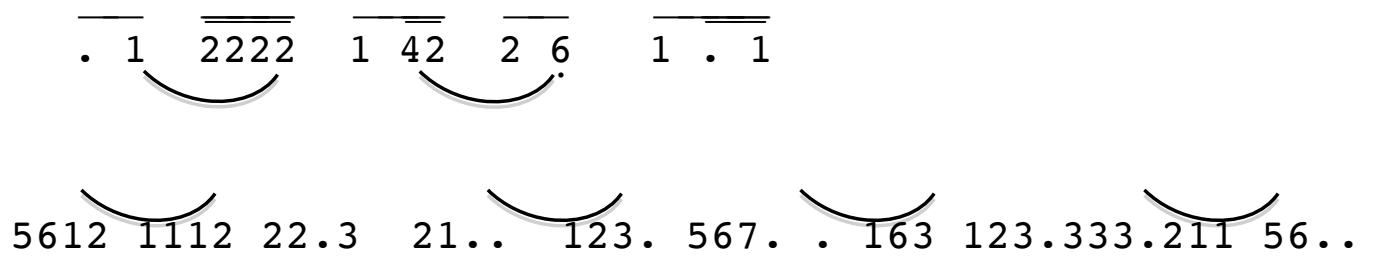

Notasi di atas dilantunkan tanpa terikat tempo.Jarak antar not (spasi) dimaksudkan untuk menandakan perkiraan rentang waktu yang diperlukan untuk melafalkan sebuah notasi.Terdapat tanda legato yang merupakan keterangan untuk menunjukan teknik vokal pada lagu seperti menyeret sambil menghentakkan not ke bawah/ ke atas. Tempo yang dihadirkan dalam wara mopoy ini adalah bertempo bebas.Panjang pendeknya nada tidak mempengaruhi tempo dalam melantunkannya.Pada bagian tertentu, terdapat wara yang menggunakan tempo terikat dengan birama 4/4.Terdapat beberapa mantra juga yang pembacaannya terkadang menggunakan pola ritme yang datar seperti tidak menggunakan pitch.Penyajiannya lebih ditekankan pada pembacaan suku kata atau kata dari syair yang disajikan.Contoh syair wara yang menggunakan beberapa nada diatas adalah sebagai berikut.

\footnotetext{
Anakng buaa lai tuqui nyeokan kelelungan

nyekanan ja waa liau tana asaq

sogat tinaq tamaq yaaq epu mollaq

tenonkai munte mate siwo dano

Nalit ningka ngawat nganam

Ngasi ngaadoq uluut munte mate siwo dano

Oppo boe siwo yeso
} 
Ennyek ukan ukun kanan naik pakai luai pancai

Ennek liau kelelungan iyek epu muntee mate

Manten nokai siwo dano

Nana aseng bungaq sogeq

Lelak lou awek ruku

Lahui ngalin lalo ningkaq

Ulun ngawa taho ngayanam

Ngasi ngadoo jawak liau

Ngawak nganam kekelungan

Adeq uluq renak galak

Maten nokai ungkong mao

Aning tulang solo lio

Konak kaling mate ningka

Enen anak panan bua

Ulun naik pantan tukui

Malas budi nyulang basa

Olo ngeruh bulang ngalak

Terjemahan bebas:

Para leluhur yang telah meninggal dan sekarang telah menjadi roh liau dan kelelungan, tetapi mereka masih mengingat para keluarga, dipanggil datang kemari karena ini sebagai balas budi dari keluarga anak cucu dengan hati ikhlas, jadi terimalah dengan suka cita dan gembira. Leluhur yang sudah meninggal akan diantarkan ke surga sehingga lebih dekat dengan Tuhan berbekal para persembahan. Ini makanan pemberian hasil jerih payah anak cucu kalian, ini makanan bersih, makanan halal, dari hasil keringat anak cucu dan menantu kalian. Silahkan makan, jangan ragu, tidak akan ditagih di kemudian hari. Anak kalian ikhas memberi dengan hati yang senang.Kelelungan dan liau menjadi perantara bagi keluarga yang masih hidup untuk berdoa juga dengan Tuhan, dan balik mendoakan sanak keluarga yang masih hidup agar mendapatkan kebaikan di dunia dari Tuhan.Dimintai tolong untuk menyampaikan permohonan orang yang masih hidup kepada Tuhan agar murah rezeki, sehat, dan dipermudah segala urusannya.

Motif ritmis ansambel kelentangan dalam iringan tari Ngerangakaw:

$$
\begin{aligned}
& \text { Gimar } \bar{t}\|: t \bar{t} \bar{t} \overline{t \cdot t} \bar{t} t \quad \bar{t} t \overline{t \cdot \bar{t}} \bar{t}:\|
\end{aligned}
$$

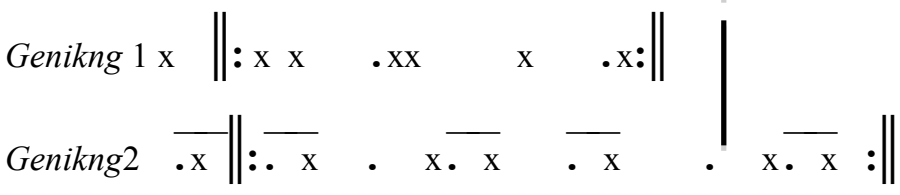

Genikng mempunyai dua pola permaianan, memainkan pukulan yang tetap pada ketukan on beatdan genikng kedua yang memainkan pola ketukan up beat. 
Genikng berfungsi sebagai peletakan dasar birama dan ketukan, memberikan aksentuasi.Pola ritme ini menggunakan birama 4/4.Aksen pukulan terdapat pada ketukan pertama (on beat). Sama halnya dengan gimarmemainkan pola ritme dengan menggunakan birama 4/4 dengan aksen pukulan terdapat pada ketukan pertama (onbeat)dalam setiap birama.Pola ritme yang dimainkan oleh kedua instrumen tersebut terkesan sederhana dan diulang-ulang.Hal ini agar suasana yang terbentuk dari awal tetap stabil, sehingga konsentrasi dan komunikasi pengewara dengan roh leluhur telah diundang hadir tetap berjalan lancar tanpa hambatan.

Pola melodi kelentangan:

Kalimat Tanya

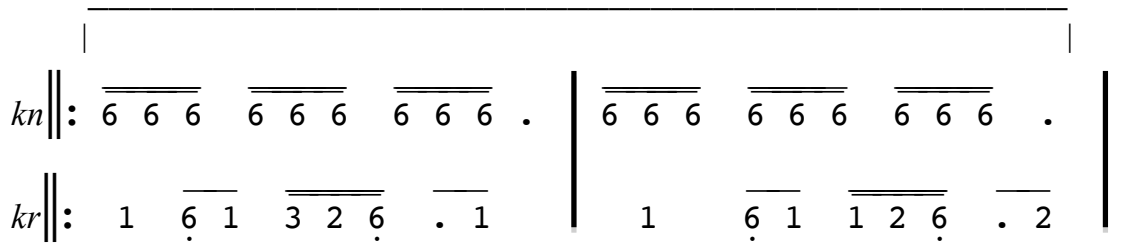

Kalimat Jawab

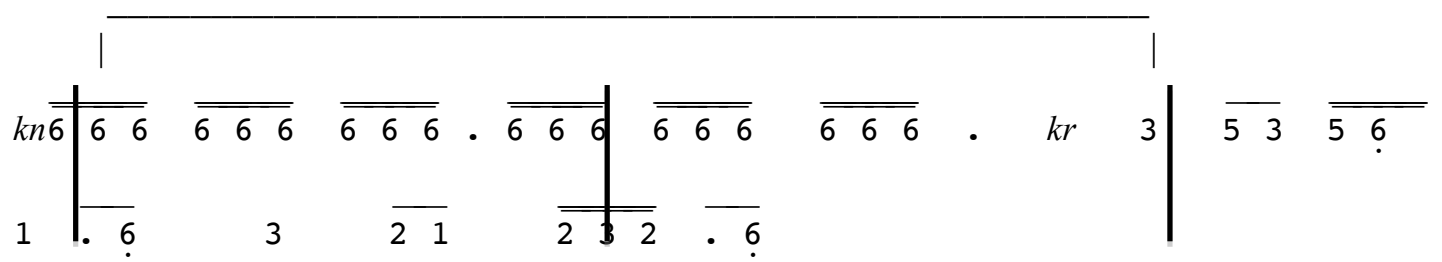

Keterangan :

$$
\begin{gathered}
\mathrm{x}=\text { ritmis genikng } \quad k n=\begin{array}{c}
\text { pola permainan kelentangan dengan } \\
\text { tangan kanan }
\end{array} \\
t=\text { ritmisgimar } \\
k r=\begin{array}{c}
\text { pola permainan kelentangan dengan } \\
\text { tangan kiri }
\end{array}
\end{gathered}
$$

Permainan kelentangan ketika mengiringi tarian Ngerangkaw memiliki tonal nada di La dengan nada dasar $\mathrm{Do}=$ Es atau dengan tangga nada $\mathrm{C}$ minor. Berikut adalah urutan tangga nada anhemitonic pentatonicyang terdapat dalam 
instrumenkelentangan di Bukit Pinang Samarinda ketika dilangsungkan upacara kwangkay tanggal 14 Januari 2017.

$\begin{array}{llllll}6 & 1 & 2 & 3 & 5 & 6 \\ \text { La } & \text { Do } & \text { Re } & \text { Mi } & \text { Sol } & \text { La }\end{array}$

Permainan musik kelentangantersebut mempunyai bagian yang diualang terus menerus samapai pertunjukan selesai, sehingga dalam melodi tidak mempunyai motif yang rumit akan tetapi mempunyai motif yang sederhana.Kesan alunannya yang sederhana dan teratur tersebut dan membentuk ikatan yang magis serta menyatu dengan langkah tarian.

\section{Kesimpulan}

Seperti suku-suku dayak yang lain, Dayak Benuaq juga memiliki adat istiadat dan kearifan lokal berbeda dalam menjalankan aturan adat. Keunikan ini terlihat dari berbagai upacara yang dilakukan dalam rangkaian kehidupan mereka dari proses kelahiran hingga kematian.Kematian menjadi sesuatu yang dilalui berdasarkan aturan dan tingkatan ritual tertentu karena mereka percaya bahwa alam baqa memiliki tingkat kehidupan yang berbeda sesuai dengan tingkat upacara yang dilaksanakan orang yang masih hidup (keluarga dan kerabat). Upacara kwangkayini terkait erat dengan asal usul dan mitologi suku dayak Benuaq yang telah membentuk dan mengikat mereka dalam suatu tatanan norma dan aturan adat Benuaq secara turun-temurun. Pelaksanaannya pun melalui berbagai syarat, tahapan, dan proses yang rumit hingga memakan waktu hingga 21 hari.

Seluruh rangkaian kegiatan yang terlaksana dari hari pertama hingga hari penutup tidak terlepas berbagai simbol dan tradisi pemberian makan kepada roh leluhur sebagai bentuk penghormatan yang tinggi terhadap leluhur. Upacara kematian kwangkay ini merupakan penghormatan dan tahap terakhir bagi mayat yang telah berumur 4-7 tahun untuk dilakukan pengangkatankembali tulang belulangnya dibawa menuju rumah dan dilaksanakan upacara penghantar roh ke 
surga melalui media penghantar yaitu waramopoy, musik kelentangan dan tari ngerangkaw.

Musik dan mantra yang hadir dalam bentuk dan alunan yang khas dan sederhana ini diulang-ulang, dipercayai memiliki kekuatan yang besar pada setiap bagian upacara. Hal ini karena musik dan mantra memiliki fungsi transendental serta hubungan magis yang dipercaya mampu menghubungkan antara roh leluhur dengan sang pencipta. Dengan demikian, jika dilihat keseluruhan prosesi dalam ritual kuwangkay ini, sangat mencerminkan tatanan dan pola kebudayaan yang kompleks yang dimiliki oleh suku Dayak Benuaq.

\title{
Daftar Pustaka
}

Emanuel. 2013. Sejarah Mitologi Suku Asli Kalimantan Timur.Surabaya : Citra Wacana.

Senen,I Wayan.2015.Bunyi-Bunyian Ritual dalam Upacara Keagamaan Hindu di Bali. Yogyakarta: Balai Penerbit Institut Seni Indonesia.

Suwardi. 1986.Upacara Tradisional (Upacara Kematian) Daerah Kalimantan Timur. Jakarta: Proyek Inventarisasi dan Dokumentasi Kebudayaan Daerah Kalimantan Timur.

Tim Penyusun Kamus. 1990. Kamus Besar Bahasa Indonesia. Jakarta: UI Press.

\author{
Nara Sumber \\ 1. Nama :Nuel \\ Umur : :60 tahun \\ Alamat : Kecamatan Mencimai, Kutai Barat, Kalimantan Timur \\ Pekerjaan :- Swasta \\ - Pengewara Adat Mencimai, Kutai Barat, Kalimantan Timur \\ 2. Nama $\quad$ :Yotam \\ Umur $\quad: 74$ tahun \\ Alamat : Bukit Pinang, Samarinda, Kalimantan Timur \\ Pekerjaan :-Swasta \\ - Pawang Adat di Bukit Pinang, Samarinda, Kalimantan Timur \\ 3. Nama : Daniel Kitok \\ Umur : 59 Tahun \\ Alamat : Kampung Jawa, Samarinda, Kalimantan Timur \\ Pekerjaan : PNS, Sekertaris Dewan Adat Benuaq Samarinda
}

